INVIVO TEST OF FOREST ONION BULBS EXTRACT (Eleutherine americana Merr.) ON THE MACROSCOPIC DESCRIPTION OF THE HEART OF WHITE RICE RATS WISTAR

(Rattus norvegicus)

\title{
UJI INVIVO EKSTRAK UMBI BAWANG HUTAN (Eleutherine americana Merr.) TERHADAP GAMBARAN MAKROSKOPIS ORGAN JANTUNG TIKUS PUTIH JANTAN GALUR WISTAR (Rattus norvegicus)
}

\author{
Greifen Triky Rondonuwu'), Herny Simbala1), Erladys Rumondor ${ }^{1)}$ \\ ${ }^{1)}$ Program Studi Farmasi FMIPA UNSRAT Manado, 95115 \\ *rondonuwugrey7gmail.com
}

\begin{abstract}
Forest onion bulbs (Eleutherine americana Merr.), Including the Iridaceae family, have been used for generations by the Dayak people as medicinal plants for various types of diseases such as breast and colon cancer, hypertension, diabetes mellitus, hypercholesterolemia and stroke. This study was conducted to evaluate the effect and side effects of extracts of forest onion bulbs to the macroscopic description of cardiac organ in rats. Thirty male white rats Wistar strain was used as research object, which is divided into three groups of dose that applied with the ethanol extract of Forest onion bulbs orally $(5 \mathrm{mg} / \mathrm{ml}, 10 \mathrm{mg} / \mathrm{ml}$, $15 \mathrm{mg} / \mathrm{ml}$ ) and one group as controls for comparison. The tests were carried out for 15 days, with observations made against the body weight of rats, macroscopic observation of cardiac organ and observation of cardiac organ weights. The results showed that the provision of forest onion bulbs extract did not cause significant changes based on the graph of observations made on the macroscopic image of the heart organ and the weight of the rats.
\end{abstract}

Keywords : Forest onion bulbs (Eleutherine Americana Merr.), cardiac macroscopic, white rat (Rattus norvegicus)

\begin{abstract}
ABSTRAK
Umbi bawang hutan (Eleutherine americana Merr.) termasuk familia Iridaceae, secara turun temurun telah dipergunakan oleh masyarakat dayak sebagai tumbuhan obat untuk berbagai jenis penyakit seperti kanker payudara dan kolon, hipertensi, diabetes mellitus, hiperkolesterol dan strok. Penelitian ini bertujuan untuk melihat pengaruh yang ditimbulkan dari konsumsi ekstrak Umbi bawang hutan terhadap gambaran makroskopis organ jantung pada tikus putih. Penelitian dilakukan menggunakan hewan percobaan tikus putih jantan galur wistar berjumlah 30 ekor, yang dibagi dalam empat kelompok dosis yang diberi ekstrak etanol umbi bawang hutan secara oral yaitu $(5 \mathrm{mg} / \mathrm{ml}, 10 \mathrm{mg} / \mathrm{ml}, 15 \mathrm{mg} / \mathrm{ml})$ dan satu kelompok kontrol sebagai pembanding. Masa pengujian dilakukan selama 15 hari, dengan pengamatan yang dilakukan berupa pengamatan berat badan tikus, pengamatan makroskopis organ jantung dan pengamatan berat organ. Hasil penelitian menunjukkan bahwa pemberian ektrak umbi bawang hutan tidak menimbulkan perubahan yang signifikan berdasarkan grafik pengamatan yang dilakukan pada gambaran makroskopis organ jantung serta penimbangan berat badan tikus.
\end{abstract}

Kata kunci : Umbi bawang hutan (Eleutherine americana Merr.), makroskopis jantung, tikus putih (Rattus norvegicus) 


\section{PENDAHULUAN}

Jantung adalah sebuah rongga organ berotot yang memompa darah lewat pembuluh darah oleh kontraksi berirama yang berulang. Istilah kardiak berarti berhubungan dengan jantung, dari kata Yunani cardia untuk jantung. Jantung adalah salah satu organ manusia yang berperan dalam sistem peredaran darah. Jantung terletak dalam rongga dada. Ukuran jantung sebesar genggaman tangan pemiliknya dengan berat sekitar 300 gram. Jantung dalam sistem sirkulasi berfungsi sebagai alat pemompa darah (Dewa dkk, 2017).

Meskipun jantung bukan organ sasaran biasa, organ ini dapat dirusak oleh berbagai jenis zat kimia. Suatu zat toksik dapat bekerja langsung pada otot jantung atau secara tidak langsung melalui susunan saraf atau pembuluh darah. Jantung merupakan organ yang potensial dan mudah diserang oleh zat toksik dan akan memompa darah yang mungkin mengandung zat toksik. Efek toksik secara histologi yang dapat timbul pada jantung diantaranya adalah atrofi jantung dan kardiomiopati (Fira, 2015).

Bawang dayak (Eleutherine americana Merr.) digunakan oleh masyarakat setempat terutama bagian umbinya untuk mengobati penyakit kanker dengan cara menumbuk bagian umbinya kemudian diperas dan airnya diminum setiap hari pada pagi hari selain itu juga ampasnya bias ditempel dibagian tubuh yang terkena kanker (payudara) (Simbala, 2015).

Kandungan yang terdapat dalam umbi bawang dayak terdiri dari senyawa flavonoid, saponin, polifenol, alkaloid, glikosida, steroid, fenolik, tanin, triterpenoid dan kuinon. Senyawa senyawa yang terkandung dalam bawang dayak yang berpotensi memiliki peran sebagai antioksidan adalah flavonoid, fenolik dan tanin (Meitary, 2017).

Hasil penelitian yang dilakukan oleh (Rizkah dkk, 2020) bahwa ekstrak etanol bawang dayak yang berasal dari Kelurahan Mongkonai, Kota Kotamobagu, Provinsi Sulawesi Utara memiliki aktivitas antioksidan yang sangat kuat dengan nilai IC50 sebesar 41,46 mg/L.

Berdasarkan uraian diatas, maka penelitian ini akan diarahkan pada pengamatan secara makroskopis organ jantung lewat hewan uji yaitu tikus putih jantan galur wistar (Rattus norvegicus) dengan pemberian ekstrak etanol dari Umbi Bawang Hutan (Eleutherine americana Merr.). Pengamatan makroskopis yang dimaksud ialah pengamatan organ yang bisa dilihat dengan mata telanjang tanpa menggunakan bantuan alat pembesar tambahan.

\section{METODOLOGI PENELITIAN Waktu dan Tempat Peneliatian}

Penelitian ini dilaksanakan di bulan januari sampai februari 2021 di laboratorium Farmasi Lanjut, Program Studi Farmasi, Fakultas MIPA, Universitas Sam Ratulangi, Manado.

\section{Alat dan Bahan}

\section{Alat}

Alat-alat yang akan digunakan adalah beaker gelas, batang pengaduk, blender, vorteks, kertas saring, ayakan, aluminium foil, timbangan analitik, oven, corong pisah, gelas ukur, botol kecil, hot plate, Sonifikator, dan cawan petri. Dan untuk pada hewan uji adalah, rak penelitian kandang tikus, Wadah makanan tikus, botol minuman tikus, kawat kasa dan dadak padi. Untuk perlakuan Hewan Uji : Sonde lambung metal, sarung tangan dan dispo. Alat untuk pembedahan: tempat otopsi (baki paraffin), jarum, gunting, pinset, pisau bedah dan toples.

\section{Bahan}

Bahan yang digunakan ialah umbi Bawang Hutan (Eleutherine americana Merr.) yang sudah masak, etanol 70\%, akuades, larutan CMC, eter, makanan (pellet) ayam.

\section{Prosedur Kerja \\ Preparasi Sampel}

Sampel umbi Bawang Dayak (Eleutherine Americana Merr.) disortasi basah lalu dicuci menggunakan air mengalir hingga bersih dari komponen pengotornya. Kemudian dikupas lapisan umbinya, dan dikeringkan ke dalam oven pada suhu $50^{\circ} \mathrm{C}$. Selanjutnya sampel yang telah kering dirajang (potong kecil-kecil) lalu disortasi kering.

\section{Ekstraksi}

Serbuk sampel umbi bawang dayak ditimbang sebanyak 500g, diekstraksi secara maserasi menggunakan pelarut etanol $70 \%$ sebanyak 2500 $\mathrm{mL}$ hingga terendam sempurna. Proses ekstraksi maserasi dilakukan dengan menggunakan wadah yang ditutupi dengan aluminiumfoil dan disimpan pada tempat yang terlindung dari sinar matahari selama 5 hari sambil sesekali diaduk. Remaserasi dilakukan sebanyak 2 kali dengan pelarut etanol $70 \%$ sebanyak $1500 \mathrm{~mL}$ selama masing-masing 3 hari. Ekstraksi dilakukan dengan metode maserasi 
karena cara pengerjaan dari metode ini sederhana dan alat-alat yang digunakan mudah untuk didapatkan. Filtrat etanol $70 \%$ yang diperoleh kemudian dikumpulkan dan diuapkan dengan oven hingga diperoleh ekstrak kental umbi Bawang Hutan. Ekstrak kental tersebut ditimbang dengan menggunakan timbangan analitik. Ekstrak kental yang sudah ditimbang kemudian disimpan dalam wadah gelas yang tertutup untuk digunakan dalam pengujian (Muharni, 2017).

\section{Pembuatan Larutan CMC (Carboxymethil Cellulose)}

Larutan $C M C$ dibuat dengan melarutkan $1 \mathrm{~g}$ $C M C$ ke dalam $30 \mathrm{~mL}$ aquadest dipanaskan sambil diaduk sampai homogen kemudian ditambahkan dengan aquadest sampai volume $100 \mathrm{~mL}$, kemudian didinginkan.

\section{Pembuatan Larutan Ekstrak Umbi Bawang Hutan (Eleutherine americana Merr.)}

Dosis pemakaian Ekstrak Umbi Bawang Hutan (Eleutherine americana Merr.) dengan faktor konversi dosis dari manusia $(70 \mathrm{~kg})$ ke hewan uji (200g) dengan dosis (400mg, 800mg, 1200mg) dikalikan 0,018 yaitu $7,2 \mathrm{mg}, 14,4 \mathrm{mg}$ dan $21,6 \mathrm{mg}$ data tersebut merupakan acuan dari penelitian ini, dan untuk penelitian ini akan menggunakan dosis yang lebih kecil yaitu $5 \mathrm{mg}$, $10 \mathrm{mg}$, dan $15 \mathrm{mg}$. Ekstrak Umbi Bawang Hutan (Eleutherine americana Merr.) ditimbang sesuai dengan dosis (g, 1,00g, dan 1,50g) disuspensikan dengan larutan CMC 0,5\% dalam masing-masing 3 labu ukur $100 \mathrm{~mL}$. Kemudian disonifikasi hingga homogen.

\section{Perlakuan}

Hewan yang digunakan adalah Tikus Putih Jantan Galur Wistar (Rattus norvegicus) sebanyak 36 ekor Pengujian dilakukan dengan 3 (tiga) kelompok perlakuan dan 1 (satu) kelompok control normal sebagai pembanding. Masingmasing kelompok terdapat 9 ekor tikus Putih Galur Wistar (Rattus norvegicus). Pemberian dosis terlebih dahulu di konversikan menggunakan factor konversi untuk manusia (70kg) ke tikus $(200 \mathrm{~g})$ dengan dikalikan 0,018.

Penelitian dilakukan perlakuan selama 15 hari, masing-masing konsentrasi menggunakan 9 hewan uji. Ekstrak Bawang Hutan (Eleutherine americana Merr.) diberikan sesuai dengan dosis, yang diberikan secara oral dengan menggunakan sonde lambung metal dan dispo $10 \mathrm{~mL}$ dengan dosis perhari 1 $1 \mathrm{cc}$ sonde lambung dimasukkan melalui mulut sampai esophagus, dimasukkan perlahan-lahan untuk menghindari refluks.

\section{Pembedahan}

Pembedahan dilakukan pada hari ke 6 , ke 11 , dan ke 16 dalam masing-masing 3 ekor tikus untuk 3 kelompok perlakuan. Tikus yang akan dibedah dimatikan dengan cara memasukkan tikus kedalam toples yang sudah ditetesi cairan eter. Kemudian Setelah beberapa saat tikus di pindahkan di letakkan diatas baki paraffin keempat kaki tikus ditusuk dengan jarum untuk mencegah gerakan-gerakan yang mengganggu pada saat pembedahan kemudian tikus siap di otopsi pembedahan diawali dengan membelah bagian perut bawah tikus hingga bagian dada, kemudian organ diambil keluar dari dalam tubuh organ yang diambil ialah organ jantung.

\section{Pengamatan Makroskopis}

Pengamatan secara makroskopis dilakukan dengan pengamatan warna, konsistensi permukaan serta penimbangan berat jantung Tikus.

\section{HASIL DAN PEMBAHASAN}

\section{Ekstraksi Ekstrak Umbi Bawang Hutan (Eleutherine americana Merr.)}

Umbi bawang hutan (Eleutherine americana Merr.) ini di ambil di Desa Passi Kabupaten Bolaang Mangodow, Sulawesi Utara. Sampel diambil sebanyak $2400 \mathrm{~g}$ selanjutnya dibersihkan dan dicuci terlebih dahulu, proses pencucian sampel bertujuan untuk membersihkan kotorankotoran atau benda asing yang menempel pada sampel kemudian diris tipis-tipis dan dikeringkan dalam suhu ruangan, proses pengeringan bertujuan untuk menurunkan kadar air sehingga bahan tidak mudah ditumbuhi bakteri dan mempermudah dalam proses pengolahan. Selanjutnya sampel diserbukkan dengan menggunakan blender dan diayak. Proses pengayakan bertujuan untuk menyeragamkan ukuran serbuk dari sampel sehingga partikel yang didapatkan tidak mempengaruhi hasil tahapan selanjutnya (Rizkah dkk, 2020).

Proses ekstraksi dilakukan dengan menggunakan metode maserasi dengan menggunakan pelarut etanol 70. Setelah di maserasi selama 5 hari dan di remaserasi sebanyak 2 kali filtrat umbi bawang hutan (Eleutherine americana Merr.) yang dihasilkan berwarna merah kehitaman hal ini sesuai dengan penelitian yang dilakukan oleh Dewa (2017). 
Kemudian Filtrat tersebut kemudian dievaporasi menggunakan oven dengan suhu $40^{\circ} \mathrm{C}$ selama $1 \mathrm{x}$ 24 jam. Evaporasi merupakan suatu proses penguapan sebagian dari pelarut sehingga didapatkan larutan zat cair pekat yang berkonsentrasi tinggi (Rizkah dkk, 2020). Setelah dievaporasi didapatkan ekstrak kental dengan pelarut etanol $70 \%$ sebanyak $15,97 \mathrm{~g}$.

Ekstrak kering kemudian dilarutkan dengan larutan CMC masing-masing sebanyak $100 \mathrm{ml}$,

Tabel 1. Gambaran makroskopis jantung tikus putih jantan galur wistar

\begin{tabular}{lllll}
\hline $\begin{array}{l}\text { Kelompok } \\
\text { Hewan Uji }\end{array}$ & Warna & Konsistensi & Berat Tikus & $\begin{array}{l}\text { Berat Organ } \\
\text { Jantung }\end{array}$ \\
\hline Kontrol & Merah kecokelatan & Kenyal & $236 \mathrm{~g}$ & $0,836 \mathrm{~g}$ \\
\hline Dosis A (5mg) & Merah kecokelatan & Kenyal & $182 \mathrm{~g}$ & $0,784 \mathrm{~g}$ \\
\hline Dosis B (10mg) & Merah kecokelatan & Kenyal & $228 \mathrm{~g}$ & $0,843 \mathrm{~g}$ \\
\hline Dosis C (15mg) & Merah kecokelatan & Kenyal & $215 \mathrm{~g}$ & $0,874 \mathrm{~g}$ \\
\hline
\end{tabular}

Tabel 1 memperlihatkan setiap kelompok perlakukan, gambaran makroskopis organ jantungnya memperlihatkan adanya warna merah kecokelatan sama dengan kelompok kontrol.

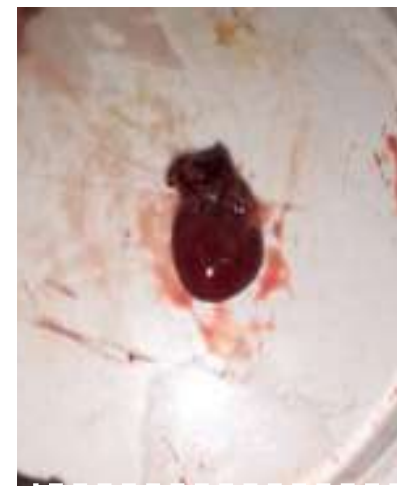

Gambar 1. Kontrol

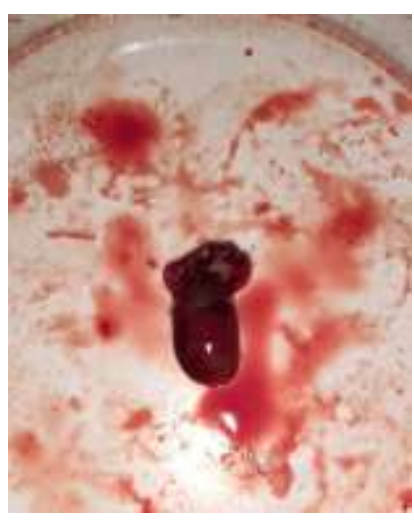

Gambar 3. Dosis B dengan 3 variasi konsentrasi 5, 10, dan 15 . Dengan cara ditimbang $0,5 \mathrm{~g}, 1,00 \mathrm{~g}$, dan 1,50 g.

\section{Gambaran Makroskopis Tikus Putih Jantan Galur Wistar (Rattus norvegicus)}

Gambaran makroskopis tikus putih jantan galur wistar (Rattus norvegicus) dapat dilihat pada Tabel 1. berat dan ukuran bervariasi antara satu kelompok dan kelompok lainnya.

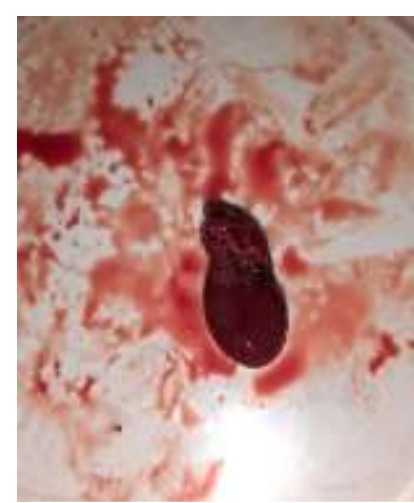

Gambar 2. Dosis A

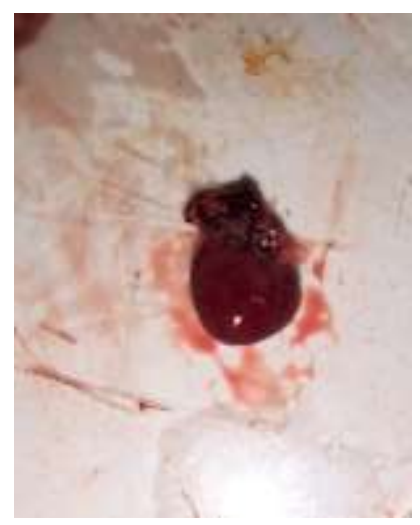

Gambar 4. Dosis C 
Jantung berfungsi sebagai alat pompa untuk mengedarkan darah, baik ke paru-paru maupun seluruh organ tubuh manusia yang lain. Karna pentingnya fungsi jantung ini maka jika terjadi suatu gangguan atau kerusakan pada organ ini akan mengakibatkan tergangunya seluruh kinerja sistem yang ada didalam tubuh manusia

Penelitian ini dilakukan dengan pemberian ektrak etanol umbi bawang hutan (Eleutherine americana Merr.) selama 15 hari tidak menimbulkan perubahan yang signifikan, gambaran makroskopis jantung tampak normal dan tidak berbeda bila dibandingkan dengan kelompok kontrol negatif. Hal ini menunjukan bahwa ekstrak etanol umbi bawang hutan (Eleutherine americana Merr.) tidak memberi efek yang dapat merusak jantung.

Hasil yang sama di peroleh dalam penelitian uji toksisitas akut ekstrak air tanaman sarang semut (Myrmecodia pendans) penampakan organ jantung yang diamati tampak normal.
Pengamatan makroskopis juga menunjukkan pemberian ekstrak tanaman sarang semut, tidak menyebabkan adanya kelainan yang berarti pada organ dan berdasarkan pengamatan patologi anatomi yang dilakukan, umumnya pemberian dosis ekstrak air tanaman sarang semut tidak menimbulkan kelainan yang menyebabkan hewan sakit (Dewa, 2017). Kemudian pada Uji Toksisitas Akut Ekstrak Etanol Daun Klausena (Clausena anisata Hook.f.) Hasil pemeriksaan mikroskopis terhadap organ jantung hewan percobaan pada kelompok yang mendapatkan perlakuan secara deskriptif dapat dikatakan tidak ditemukan adanya perubahan yang berarti (Yusuf, 2011)

\section{Hasil Penimbangan Berat Badan tikus Putih Jantan Galur Wistar(Rattus norvegicus)}

Data rata-rata hasil penimbangan berat badan tikus setelah perlakuan dapat dilihat pada gambar 5 .

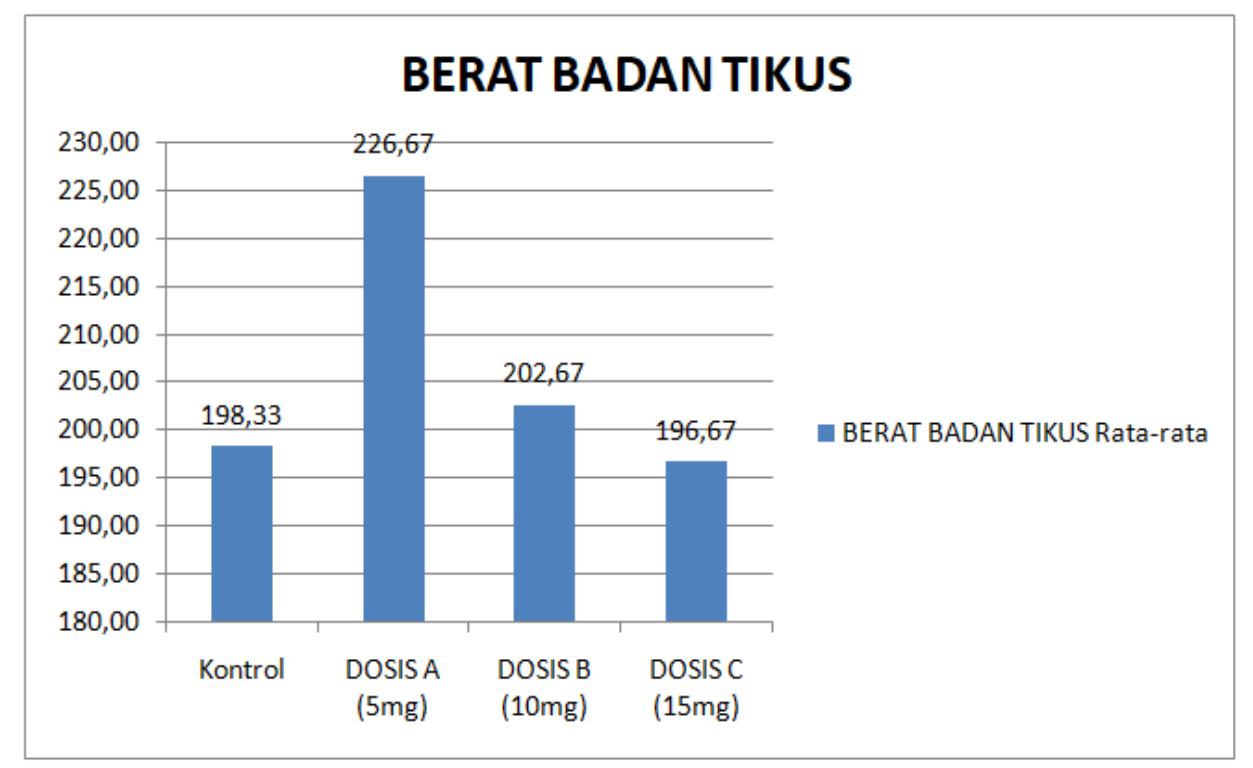

Gambar 5. Grafik rata- rata hasil penimbangan berat badan tikus wistar (Rattus norvegicus)

Penimbangan berat badan hewan uji bertujuan untuk mengetahui kesehatan hewan uji serta memantau perubahan berat badan pada hasil rata rata penimbangan berat badan tikus tiap kelompok perlakuan diatas terdapat perubahan berat badan antara kelompok perlakuan dengan kelompok kontrol. Pengukuran berat badan tikus adalah salah satu data pendukung guna melihat pengaruh toksisitas.

Berdasarkan data grafik rata-rata penimbangan berat badan tikus pada gambar 7 dapat dilihat bahwa perlakuan yang menunjukkan penurunan berat badan paling rendah terdapat pada dosis c $15 \mathrm{mg}$, sedangkan berat badan yang paling tinggi terdapat pada kelompok dosis a 5mg. Akan tetapi perubahan berat badan pada tikus wistar yang mendapat perlakuan tidak begitu berbeda, bila dibandingkan dengan kelompok kontrol. Terjadinya perubahan berat badan tikus dapat dikarenakan adanya proses pertumbuhan yang dialami oleh tikus, dan juga adanya pengaruh pemberian ekstrak etanol umbi bawang hutan (Eleutherine americana Merr.). Berdasarkan hasil penelitian yang dilakukan oleh Kuncarli and 
Djunarko (2014), uji toksisitas subkronis infusa daun Sirih merah terhadap gambaran makroskopis jantung pada hasil penelitiannya pada pengukuran berat badan tikus jantan menunjukkan hasil yang berbeda bermakna antara kelompok perlakuan dan kontrol aquadest, terjadinya perubahan berat badan dapat dikarenakan proses pertumbuhan yang dialami oleh tikus jantan maupun betina dan adanya pengaruh dari pemberian infusa daun sirih merah, dan disimpulkan bahwa pemberian infusa daun Sirih merah maupun kontrol pemberian aquadest menunjukkan peningkatan dan penurunan, namun tidak menunjukkan hasil perbedaan yang bermakna.

Penelitian yang berjudul Uji toksisitas buah Pinang yaki (Areca vestiaria). menggunakan Metode BSLT (Brine Shrimp Lethality Test) (Simbala, 2007) pada penelitian tersebut konsentrasi ekstrak Pinang yaki (Areca vestiaria). yang digunakan dalam uji toksisitas yaitu 400, 600,800 , dan 1000ppm. Hasil penelitian menunjukkan ekstrak biji pinang yaki (Areca vestiaria). memiliki potensi bioaktif, dalam hal ini berada pada nilai LC50 sebesar 334.99 ppm, berarti pada konsenrasi tersebut menyebabkan kematian 50\% hewan uji Nilai tersebut menunjukkan bahwa secara farmakologis bersifat toksik terhadap hewan uji.

\section{Hasil Penimbangan Berat Organ Jantung Tikus Putih Jantan Galur Wistar (Rattus norvegicus)}

Data rata-rata hasil penimbangan berat organ jantung tikus putih jantan galur wistar (Rattus norvegicus) setelah perlakuan dapat dilihat pada gambar 6.

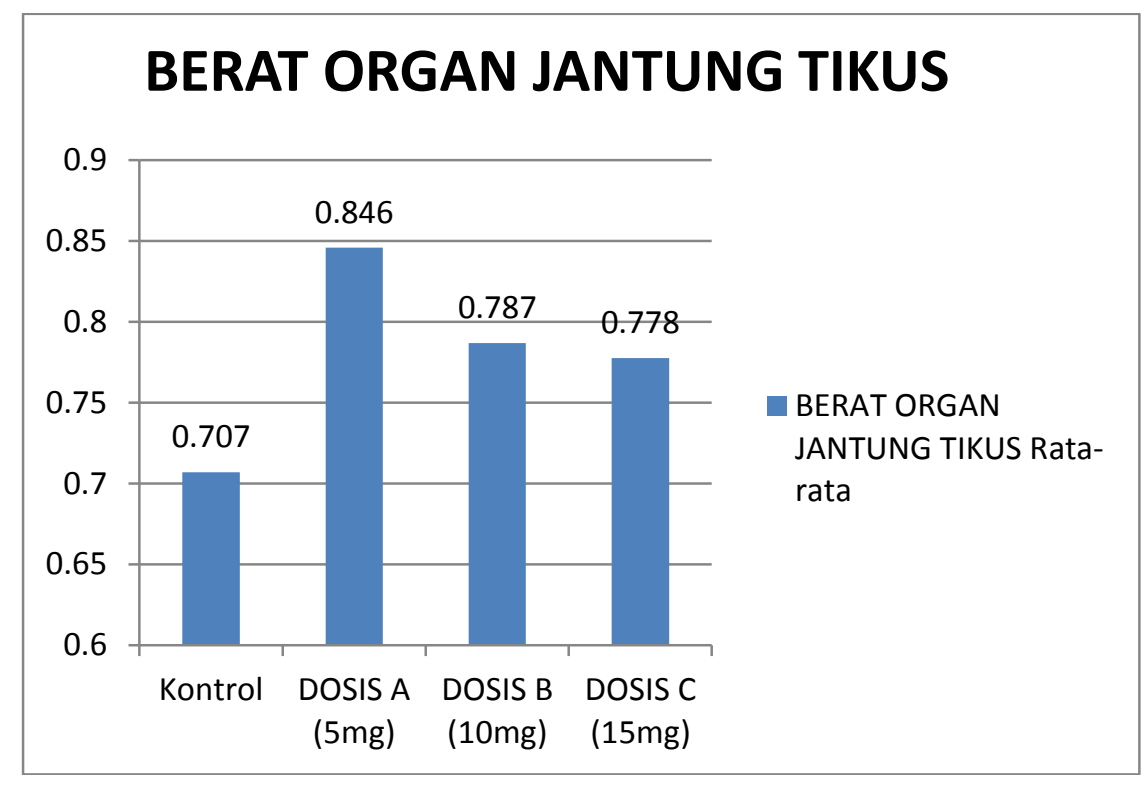

Gambar 6. Grafik rata- rata hasil penimbangan berat organ jantung tikus putih jantan galur wistar (Rattus norvegicus)

Berdasarkan hasil grafik penimbangan berat jantung tikus di atas menunjukkan bahwa hasil rata-rata perubahan berat organ jantung pada kelompok perlakuan dosis A $(5 \mathrm{mg})$, dosis B (10mg), dan dosis C (15mg) tidak begitu berbeda bila dibandingkan dengan data sebelumnya pada rata-rata berat badan tikus wistar, yaitu dari keempat kelompok perlakuan yang menunjukkan penurunan berat badan paling rendah terdapat pada dosis C (15mg) dan kelompok kontrol, sedangkan berat badan paling tinggi terdapat pada kelompok dosis A (5mg). Akan tetapi perubahan berat badan pada tikus wistar yang mendapat perlakuan tidak begitu berbeda, bila dibandingkan dengan kelompok kontrol negatif.

Hasil ini di dukung oleh penelitian yang dilakukan oleh Dewa (2017) yang berjudul Pengaruh Ekstrak Etanol Buah Pinang yaki (Areca vestiaria) terhadap sGambaran Makroskopis Organ Jantung pada Tikus Putih Jantan Galur Wistar (Rattus norvegicus). data yang didapat dalam penimbangan hasil rata-rata perubahan berat organ jantung pada kelompok perlakuan A400, A800 dan A1200 tidak jau berbeda dibandingkan dengan data sebelumnya, yaitu dari keempat kelompok perlakuan yang menunjukkan penurunan berat badan paling rendah terdapat pada dosis A400, sedangkan 
berat badan paling tinggi terdapat pada kelompok kontrol negative. Perubahan berat badan tersebut tidak begitu berbeda, bila dibandingkan dengan kelompok kontrol negatif.

\section{KESIMPULAN}

Berdasarkan hasil penelitian yang didapatkan bahwa umbi bawang hutan (Eleutherine americana Merr.) tidak berpengaruh terhadap gambaran makroskopis organ jantung pada tikus putih jantan galur wistar (Rattus norvegicus) dan pada hasil penimbangan rata-rata berat badan dan berat organ jantung tikus berdasarkan grafik tidak terjadi perbedaan yang signifikan berat organ kelompok kontrol, dosis A (5mg), dosis B (10mg), dan dosis C (15mg). Hal ini menunjukan bahwa ekstrak etanol umbi bawang hutan (Eleutherine americana Merr.) tidak memberi efek yang dapat merusak jantung.

\section{SARAN}

1. Apabila melakukan penelitian lebih lanjut pada bagian lain tumbuhan bawang hutan seperti akar, daun, dan batang mengunakan metode yang berbeda agar didapatkan informasi lebih mendalam sehingga dapat dijadikan acuan untuk penelitian selanjutnya.

2. Apabila melakukan penelitian yang sama atau sejenis perlu dilakukan pengamatan histopatologi pada organ jantung tikus wistar, agar potensi keamanan suatu zat kimia lebih jelas serta dilakukan second observer oleh ahli patologi anatomi

\section{DAFTAR PUSTAKA}

Fira, R. A. 2015. Uji Toksisitas Subkronik Ekstrak Air Daun Katuk (Sauropus androgynus (L.) Merr.) Terhadap Berat Jantung Dan Histologi Jantung Tikus Putih (Rattus norvegicus) Betina.

Dewa I. A. R, Widdhi B, Herny Simbala. 2017. Pengaruh Ekstrak Etanol Buah Pinang Yaki (Areca vestiaria) Terhadap Gambaran Makroskopis Organ Jantung Pada Tikus Putih Jantan (Rattus novergicus) Galur Wistar. FMIPA UNSRAT, Manado

Meitary, N. 2017. Analisis Total Fenol, Flavonoid, Dan Tanin Serta Aktivitas Antioksidan Empat Ekstrak Daun Jati Belanda (Guazuma Ulmifolia). Skripsi. Institut Pertanian Bogor. Bogor.
Rizkah, V. N. 2020. Uji Aktivitas Antioksidan Ekstrak Etanol Bulbus Bawang Dayak (Eleutherine americana Merr.) Dengan Metode DPPH (1,1-Diphenyl-2Picrylhydrazyl) FMIPA UNSRAT, Manado.

Simbala, H.E.I. 2007. Uji Toksisitas dan Uji Preklinik Areca vestiaria/Pinang yaki sebagai antifertilitas UNSRAT, Manado.

Simbala., de Queljoe E. 2015. Biodiversitas Tumbuhan Obat di Sulawesi Utara. Putra Media Grafindo Bandung:12.

Yusuf, H. 2011. Uji Toksisitas Akut Ekstrak Etanol Daun Klausena (Clausena anisata Hook.f.). 11:1. 